\title{
Stigmata of Chronic Liver Disease
}

National Cancer Institute

\section{Source}

National Cancer Institute. Stigmata of Chronic Liver Disease. NCI Thesaurus. Code C82996.

Signs of chronic liver disease which include jaundice, ascites, palmar erythema, spider hemangiomas, gynecomastia, and encephalopathy. 